\title{
Antioxidant Effect of L-carnitine in Rats Fed Cholesterol Rich Diet
}

\author{
Ercan Keskin ${ }^{1}$, Deniz Uluisik ${ }^{1,}$, , Mehmet Altin ${ }^{2}$ \\ ${ }^{1}$ Department of Physiology, Faculty of Veterinary Medicine, University of Selcuk, Konya, Turkey \\ ${ }^{2}$ School of Physical Education and Sports, University of Selcuk, Konya, Turkey \\ Email address: \\ ekeskin@selcuk.edu.tr (E. Keskin), denizfedai@selcuk.edu.tr(D. Uluisik), mealtin@selcuk.edu.tr (M. Altin)
}

\section{To cite this article:}

Ercan Keskin, Deniz Uluisik, Mehmet Altin. Antioxidant Effect of L-carnitine in Rats Fed Cholesterol Rich Diet. Animal and Veterinary Sciences. Vol. 3, No. 4, 2015, pp. 113-116. doi: 10.11648/j.avs.20150304.13

\begin{abstract}
This study was conducted to assess the effects of L-carnitine on antioxidant enzymes in rats fed cholesterol rich diet. A total of 32 healthy male Wistar Albino rats were allocated to four groups. Animals of the first group were fed standard rat pellets, animals of the second group were fed standard rat pellets that contained $7.5 \%$ cholesterol powder, animals of the third group were fed standard rat pellets and water contained $75 \mathrm{mg} / \mathrm{l} \mathrm{L}$-carnitine while those of the forth group were fed standard rat pellets that contained $7.5 \%$ cholesterol and water that contained $75 \mathrm{mg} / \mathrm{l}$ L-carnitine for 40 days. On the 40 th day of the study, blood samples were taken from all animals and thiobarbituric acid reactive substances (TBARS), glutathione (GSH), superoxide dismutase (SOD), glutathione peroxidase (GPx) and catalase (CAT) levels were determined. The results showed that feeding with high cholesterol diet resulted significantly increase in TBARS level and decreases in GSH, SOD, GPx levels when compared to control group $(\mathrm{p}<0.05)$. L-carnitine addition to the high cholesterol diet significantly decreased in TBARS level and increased in GSH, SOD levels compared to cholesterol group $(\mathrm{p}<0.05)$. In conclusion, our results showed L-carnitine may be useful an antioxidant in hypercholesterolemic condition.
\end{abstract}

Keywords: L-carnitine, Cholesterol, Antioxidants, Lipid Peroxidation, Rat

\section{Introduction}

Oxidative stress is occurred by the existence of free radicals or radical-producing agents in levels that exceed natural radical-blocking or -scavenging mechanisms $[1,2]$. There are many sources of oxidative stress including some disorders such as diabet, hypercholesterolemia, hyperlipidemia, obesity $[3,4,5,6]$.

The antioxidant system consists of low molecular weight antioxidant molecules, such as glutathione and various antioxidant enzymes. Superoxide dismutase is the first line of defense against oxygen-derived free radicals, catalysis the dismutation of superoxide anion into $\mathrm{H}_{2} \mathrm{O}_{2} . \mathrm{H}_{2} \mathrm{O}_{2}$ can be transformed into $\mathrm{H}_{2} \mathrm{O}$ and $\mathrm{O}_{2}$ by catalase. Glutathione peroxidase reduces lipidic or nonlipidic hydroperoxides as well as $\mathrm{H}_{2} \mathrm{O}_{2}$ while oxidizing $\mathrm{GSH}[7,8]$. The process of lipid peroxidation is one of oxidative conversion of polyunsaturated fatty acids to products known as malondialdehyde (MDA) or lipid peroxides [9, 10].

$\mathrm{L}$-carnitine is a natural nutrient related to $\mathrm{B}$ vitamins that is essential for the $\beta$-oxidation of fatty acids in mitochondria to generate adenosine triphosphate. The protective effects of Lcarnitine on the metabolism of tissues in organs (heart, brain and liver) have been studied [11]. L-carnitine has been reported to protect cell against free radical damage and lipid peroxidation [12, 13] Carnitines are essential factors of several enzymes necessary for the transformation of longchain fatty acids, and act also as scavengers of oxygen free radicals in mammalian tissues $[10,14]$.

The objective of the present work is to study the influence of L-carnitine on oxidative status (TBARS, GSH, SOD, GPX and CAT) in rats fed cholesterol rich diet.

\section{Materials and Methods}

The study was conducted on 32 healthy male Wistar Albino rats. The rats were allocated to four groups consist of eight animals each. The mean weights of all groups were similar. All rats were kept in individual cages during the 40 days of experiment and were fed ad libitum as follows: animals of the first group were fed standard rat pellets (Purina $^{\circledR}$, Optima Besin Maddeleri San. ve Tic. A.Ş., Balıkesir, Turkey), while those of the second group were fed 
standard rat pellets that contained $7.5 \%$ cholesterol powder (Sigma-Aldrich, Steinheim, Germany), but the animals of the third group were fed standard rat pellets and water contained $75 \mathrm{mg} / \mathrm{l}$ L-carnitine (Solgar Vitamin and Herb, Leonia, NJ) and the animals of the forth group were fed standard rat pellets that contained $7.5 \%$ cholesterol and water that contained $75 \mathrm{mg} / \mathrm{l} \mathrm{L}$-carnitine. On the 40 th day of the study, blood samples were taken from all animals. The TBARS, GSH, SOD, GPx and CAT (Cayman Chemical, Ann Arbor, MI, USA) levels were determined in the plasma samples using a commercial sandwich enzyme-linked immunosorbent assay (Bio-Tek Instruments, Inc). The data were analyzed using one-way ANOVA (SPSS 17). Differences among the groups were determined by Duncan's multiple range tests. Differences were considered significant at $\mathrm{p}<0.05$.

\section{Results}

The levels of TBARS, GSH, SOD, GPx and CAT obtained from all groups were shown in Table 1. Feeding with high cholesterol diet resulted significantly increase in TBARS level and decreases in GSH, SOD, GPx levels when compared to control group (Table $1, \mathrm{p}<0.05$ ). L-carnitine addition to the high cholesterol diet significantly decreased in TBARS level and increased in GSH, SOD levels compared to cholesterol group (Table $1, \mathrm{p}<0.05$ ). The levels of these enzymes in L-carnitine group were not different than that of control group levels. It was not found any difference in CAT levels of cholesterol group and L-carnitine+cholesterol group compared to control group.

Table 1. The effects of L-carnitine on TBARS, GSH, SOD, GPX and CAT levels in rats fed cholesterol rich diet (Mean $\pm S E)$.

\begin{tabular}{lllll}
\hline Group $(\mathbf{n}=8)$ & TBARS $(\boldsymbol{\mu M})$ & GSH $(\boldsymbol{\mu M})$ & SOD $(\mathbf{U} / \mathbf{m l})$ & GPx $(\mathbf{n m o l} / \mathbf{m i n} / \mathbf{m l})$ \\
\hline Group 1 & $3.61 \pm 0.38^{\mathrm{bc}}$ & $43.75 \pm 3.99^{\mathrm{a}}$ & $23.38 \pm 3.09^{\mathrm{a}}$ & $32.13 \pm 3.03^{\mathrm{a}}$ \\
Group 2 & $5.65 \pm 0.47^{\mathrm{a}}$ & $27.75 \pm 2.03^{\mathrm{b}}$ & $13.25 \pm 1.25^{\mathrm{b}}$ & $37.75 \pm 5.02^{\mathrm{ab}}$ \\
Group 3 & $3.14 \pm 0.37^{\mathrm{c}}$ & $39.88 \pm 3.83^{\mathrm{a}}$ & $25.38 \pm 3.98^{\mathrm{a}}$ & $18.25 \pm 2.46^{\mathrm{b}}$ \\
Group 4 & $4.50 \pm 0.34^{\mathrm{b}}$ & $38.25 \pm 2.85^{\mathrm{a}}$ & $21.50 \pm 1.09^{\mathrm{a}}$ & $29.13 \pm 2.87^{\mathrm{a}}$ \\
\hline
\end{tabular}

The difference between mean values with different superscripts in the same column is significant for each parameter, $\mathrm{p}<0.05$.

Group 1, control; group 2, cholesterol; group 3, L-carnitine; group 4, L-carnitine+cholesterol.

\section{Discussion}

It has been shown that animals and humans had an effective process to prevent the free radical induced tissue cell damage. This process is achieved by some antioxidant enzymes and proteins such as SOD, CAT, GPx and GSH [15, $16,17]$. If the balance between ROS production and antioxidant defense is lost, oxidative stress occurs [15, 17]. Our results showed that the plasma TBARS level significantly increased feeding with high cholesterol diet when compared to first group feeding with standard diet (Table $1, \mathrm{p}<0.05$ ). In respect of antioxidant enzymes activities, we found statically important decreases in plasma GSH, SOD, and GPx levels in rats fed high cholesterol diet compared to first group feeding with standard diet (Table 1, $\mathrm{p}<0.05$ ). These results reflect the oxidative stress and lipid peroxidation resulting from hypercholesterolemia. Under our experimental condition, the increase TBARS and the decrease GSH levels in the hypercholesterolmic group are consistent with the data reported by Sayed-Ahmed et al. [18] and Steinberg [19]. There are some mechanisms suggesting the reduction of antioxidant enzymes in hypercholesterolemia. The increased lipid peroxidation lead to inactivation of the enzymes by crosses linking with MDA; this will cause an increased accumulation of superoxide, $\mathrm{H}_{2} \mathrm{O}_{2}$ and hydroxyl radicals which could further stimulate lipid peroxidation [15]. On the other hand, decrease of antioxidant enzyme may be due to rapid consumption and exhaustion of storage of this enzyme in fighting free radicals generated during hyperlipidemia [15].

There are several experimental and clinical studies that reported the efficacy of L-carnitine supplementation in cardiovascular diseases and/or atherosclerosis [20, 21, 22,
23]. However, L-carnitine is important component in lipid metabolism for production adenosine triphosphate via $\beta$ oxidation and subsequent oxidative phosphorylation $[24,25$, 26]. It has been reported that there is a decrease in the concentration of carnitine in blood and tissues in hyperlipidemic condition [27]. In atherosclerotic and hyperlipidemic condition there was a depletion of carnitine, resulting in a decrease in the transport of fatty acid into mitochondria [24]. Thus, Carnitine has also received consideration as a hypolipidemic agent [28]. Further carnitine is reported to exert antioxidant action in experimental animals $[14,28]$.

In our study, L-carnitine supplementation significantly reduced TBARS level and increased GSH and SOD levels in L-carnitine+cholesterol group compared to cholesterol group (Table 1, $\mathrm{p}<0.05$ ) suggesting that L-carnitine has an antioxidant effect. Although the changes in GPx and CAT levels were not important of L-carnitine+cholesterol group compared to cholesterol group, the levels of these enzymes were close to that of control group. Sayed-Ahmed et al. [18] and Steinberg [19] reported that L-carnitine prevented the increase in MDA and the decrease in GSH induced by a hypercholesterolemic diet. Dayanandan et al. [24] noted elevation in GSH and GPx levels with carnitine supplementation in rats. On the other hand, Rajasekar et al. [28] found significantly increases antioxidant enzyme levels (GSH, SOD, CAT and GPx) of rats treated with L-carnitine compared to untreated rats. In our study, decrease in TBARS level and increase antioxidant enzymes with L-carnitine treatment may be due to enhancement of transport of fatty acids by carnitine into mitochondria for energy production [24]. In addition to its hypolipidemic and hypocholoesterolemic effects, it has reported that carnitine 
inhibits the microsomal peroxidation and it has a role in chelating free $\mathrm{Fe}^{2+}$ ions and by this way it reduces free radical generation $[24,29,30]$.

\section{Conclusion}

In conclusion, our results showed L-carnitine may be useful an antioxidant in hypercholesterolemic condition. Its beneficial effects may be attributed to its both direct hypolipidemic properties and possible antioxidant mechanisms.

\section{References}

[1] Halliwell, B. and Gutteridge, J. M. (1990). Free radicals in biology and medicine. Oxford, United Kingdom: Clarendon Press.

[2] Block, G., Dietrich, M., Norkus, E. P., Morrow, J. D., Hudes, M., Caan, B. and Packer, L. (2002). Factors Associated with Oxidative Stress in Human Populations. Am. J. Epidemiol., 156: $274-285$

[3] Evans, J. L., Goldfine, I. D., Maddux, B. A. and Grodsky, G. M. (2002). Oxidative Stress and Stress-Activated Signaling Pathways: A Unifying Hypothesis of Type 2 Diabetes. Endocrine Reviews, 23(5): 599-622.

[4] Khan, N. I., Naz, L. and Yasmeen, G. (2006). Obesity: an independent risk factor for systemic oxidative stress. Pakistan J. Pharm. Sci., 19(1): 62-65.

[5] Marseglia, L., Manti, S., D'Angelo, G., Nicotera, A., Parisi, E., Di Rosa, G., Gitto, E. and Arrigo, T. (2015). Oxidative stress in obesity: a critical component in human diseases. Int. J. Mol. Sci., 16(1): 378-400.

[6] Keaney, J. F. and Vita, J. A. (1995). Atherosclerosis, Oxidative Stress, and Antioxidant Protection in Endothelium-Derived Relaxing Factor Action. Prog. Cardiovasc. Dis., 38(2): 129154.

[7] Polat, M. F., Taysi, S., Gül, M., Çıkman, O., Yılmaz, I., Bakan, E. and Erdogan, F. (2002). Oxidant/antioxidant status in blood of patients with malignant breast tumor and benign breast disease. Cell Biochemistry Function, 20(4): 327-331.

[8] Taysi, S., Polat, F., Gül, M., Sarı, R. A. and Bakan, E. (2002). Lipid peroxidation, some extracellular antioxidants and antioxidant enzymes in serum of patients with rheumatoid arthritis. Rheumatology International, 21(5): 200-204.

[9] Taysi, S., Uslu, C., Akçay, F. and Sütbeyaz, M. Y. (2002). Levels of malondialdehyde and nitric oxide in plasma of patients with advanced laryngeal cancer. Surgery Today, 33: 651-654.

[10] Mansour, H. H. (2006). Protective role of carnitine ester against radiation-induced oxidative stress in rats. Pharmacological Research, 54(3): 165-171.

[11] Demirdağ, K., Bahcecioğlu, I. H., Ozercan, I. H., Ozden, M., Yilmaz, S. and Kalkan, A. (2004). Role of L-carnitine in the prevention of acute liver damage induced by carbon tetrachloride in rats. Journal of Gastroenterology and Hepatology, 19(3): 333-338.
[12] Sener, G., Paskaloğlu, K., Satiroglu, H., Alican, I., Kaçmaz, A. and Sakarcan, A. (2004). L-carnitine ameliorates oxidative damage due to chronic renal failure in rats. Journal of Cardiovascular Pharmacology, 43(5): 698-705.

[13] El-khishin, I. A. and Amer, M. G. (2010). Possible Protective Role of L-carnitine on Diclofenac Induced Hepatotoxicity in Adult Male Albino Rats (Histological, Immunohistochemical and Biochemical Study). Egyptian Journal of Histology, 33(2): 341-352.

[14] Izgut-Uysal, V. N., Ağaç, A. and Derin, N. (2001). Effect of carnitine on stress-induced lipid peroxidation in rat gastric mucosa. Journal of Gastroenterology, 36(4): 231-236.

[15] Noeman, S. A., Hamooda, H. E. and Baalash, A. A. (2011). Biochemical Study of Oxidative Stress Markers in the Liver, Kidney and Heart of High Fat Diet Induced Obesity in Rats. Diabetology \& Metabolic Syndrome, 3(17): 1-8.

[16] Mishra, K. P. (2004). Cell membrane oxidative damage induced by gamma radiation and apoptotic sensitivity. Journal of Environmental Pathology, Toxicology and Oncology, 23(1): 61-66.

[17] Blokhina, O., Virolainen, E. and Fagerstedt, K. V. (2003). Antioxidants, Oxidative Damage and Oxygen Deprivation Stress a Review. Annals Botany, 91: 179-194.

[18] Sayed-Ahmed, M. M., Khattab, M. M., Gad, M. Z. and Mostafa, N. (2001). L-carnitine prevents the progression of atherosclerotic lesions in hypercholesterolaemic rabbits. Pharmacological Research, 44(3): 235-242.

[19] Steinberg, D. (1995). Role of oxidized LDL and antioxidants in atherosclerosis. Advances Experimental Medicine and Biology, 369: 39-48.

[20] Seccombe, D. W., James, L., Hahn, P. and Jones, E. (1987). Lcarnitine treatment in the hyperlipidemic rabbit. Metabolism, 35: 1192-1196.

[21] Spagnoli, L. G., Orlandi, A., Mauriello, A., DeAngelis, C. and Ramacci, M. T. (1995). Propionyl-1-carnitine prevents the progression of atherosclerotic lesions in aged hyperlipemic rabbits. Atherosclerosis, 114: 28-44.

[22] Hiatt, W. R., Nawaz, D. and Brass, E. P. (1987). Carnitine metabolism during exercise in patients with peripheral vascular disease. J. Appl. Physiol., 62(6): 2383-2387.

[23] Hiatt, W. R. and Brass, E. P. (1992). Carnitine metabolism in peripheral arterial disease. In: L-carnitine and its role in medicine: from function to therapy. Ferrari, R., Dimauro, S., Sherwood, G., Eds. London NW1 7DX: Academic Press Limited, 354-363.

[24] Dayanandan, A., Kumar, P. and Panneerselvam, C. (2001). Protective role of L-carnitine on liver and heart lipid peroxidation in atherosclerotic rats. Journal of Nutritional Biochemistry, 12: 254-257.

[25] Carter, A. L., Abney, P. O. and Lapp, F. D. (1995). Biosynthesis and metabolism of carnitine. Journal of Child Neurology, 10(2): 253-257.

[26] Flanagan, J. L., Simmons, P. A., Vehige, J., Willcox, M. DP. and Garrett, Q. (2010). Role of carnitine in disease. Nutrition and Metabolism, 7: 1-14. 
[27] Seccombe, D. W., James, L., Peter, H. and Jones, E. (1987). Lcarnitine treatment in hyperlipidemic rabbit. Metabolism, 36(12): 1192-1196.

[28] Rajasekar, P., Ravichandran, M. K. and Anuradha, C. V. (2005). Intraperitoneal L-carnitine regulates lipid metabolism and reduces oxidative stress in fructose-induced hyperlipidemic rats. Diabetologia Croatica, 34(3): 87-95.

[29] Reznick, A. K., Kagen, V. E., Ransey, R., Tsuchiya, M.,
Serbinova, E. A. and Packer, L. (1992). Antiradical effect in L-propionyl carnitine protection of the heart against ischemic reperfusion injury. The possible role of ion chelation. Archives Biochemistry Biophysics, 296(2): 394-401.

[30] SushamaKumari, S., Jayadeep, A., Kumar, J. S. and Menon, V. P. (1989). Effect of carnitine on malondyaldehyde, taurine and glutathione levels in the heart of rats subjected to myocardial stress by isoproteinol. Indian Journal of Experimental Biology, 27(2): 134-137. 